\title{
Association of IL12B polymorphisms with susceptibility to Graves ophthalmopathy in a Taiwan Chinese population
}

\author{
Yu-Huei Liu ${ }^{1,2}$, Ching-Chu Chen ${ }^{3,4}$, Li-Ling Liao ${ }^{5}$, Lei Wan ${ }^{1,6}$, Chang-Hai Tsai ${ }^{7,8}$ and Fuu-Jen Tsai ${ }^{1,6,7,9,10,11^{*}}$
}

\begin{abstract}
Background: Interleukin 12B (IL 12B) gene polymorphisms have been linked to several inflammatory diseases, but their role in the development of Graves ophthalmopathy (GO) in Graves disease (GD) patients is unclear. The purpose of this study was to investigate the disease association of $I L 12 B$ single nucleotide polymorphisms (SNPs).

Methods: A Taiwan Chinese population comprising $200 \mathrm{GD}$ patients with GO and $271 \mathrm{GD}$ patients without GO was genotyped using an allele-specific extension and ligation method. Hardy-Weinberg equilibrium was estimated using the chi-square test. Allele and genotype frequencies were compared between GD patients with and without GO using the chi-square test.

Results: The genotype and allele frequencies of examined SNPs did not differ between GD patients with and without GO. Although the genotype distribution remained nonsignificant in the sex-stratified analyses, the frequency of the $T$ allele at SNP rs 1003199 was significantly higher in patients with $\mathrm{GO}$ in the male cohort $\left(P=6.00 \times 10^{-3}\right)$. In addition, haplotypes of ILI2B may be used to predict the risk of $\mathrm{GO}\left(P=1.70 \times 10^{-2}\right)$; however, we could not prove the statistical significance of analysis after applying the Bonferroni correction.

Conclusions: Our results provide new information that the examined $I L 12 B$ gene polymorphisms may be associated with susceptibility to $\mathrm{GO}$ in the Taiwan Chinese population in a sex-specific manner. This conclusion requires further investigation.
\end{abstract}

\section{Background}

Graves ophthalmopathy (GO) is a type of fibroproliferative autoimmune disease, which is characterized by inflammation, remodeling, and expansion of the retroocular fibroblasts of the eye. This disease commonly occurs in patients with Graves disease (GD) and serves as a major characteristic that is observed in $25-50 \%$ of patients with GD [1-5]. Although GO may develop from the activity of thyroid-stimulating hormone (TSH) receptor-stimulating antibodies [6-9], which are strongly associated with hyperthyroidism and GO, the mechanisms linking GD and GO remain largely elusive [10-12]. Recently, studies have suggested that cytokines may play a crucial role in regulating the development of GD and GO

\footnotetext{
* Correspondence: d0704@mail.cmuh.org.tw

1 Department of Medical Genetics and Medical Research, China Medical University Hospital, Taichung, Taiwan

${ }^{6}$ School of Chinese Medicine, China Medical University, Taichung, Taiwan Full list of author information is available at the end of the article
}

[13]; however, the detailed mechanisms thereof remain largely unclear.

Interleukin 12B (IL12B; OMIM 161561), which is located on chromosomal region $5 \mathrm{q} 33.3$, encodes the $\mathrm{p} 40$ subunit of the cytokines IL12 and IL23, which play a pivotal role in both innate and adaptive immunity [14]. Although the role of interleukins in the development of GO in GD patients is little known, thyroid hormones have been known to increase the secretion of IL12, which regulates dendritic cell maturation and function [15]. IL12 has been reported to be overexpressed during the active phase of GD and GO [16,17]. On the other hand, IL23 expression could be induced in fibroblastlike synoviocytes through active IL1B, a well-known GO-related cytokine in rheumatoid arthritis, in AP1-dependent and nuclear factor-kappa B-dependent pathways [18-21]. These studies implied that $\mathrm{p} 40$, which is encoded by $I L 12 B$, might be involved in regulating inflammation.

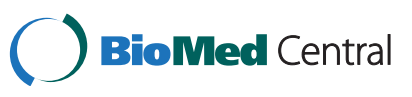


Table 1 Inclusion/exclusion criteria

\begin{tabular}{ll}
\hline Criteria & Details \\
\hline Inclusion & $\begin{array}{l}\text { Patients must understand risks and benefits of the protocol } \\
\text { and be able to give informed consent. }\end{array}$ \\
& Patient is a self-reported non-aboriginal Taiwanese, \\
& and none of the parents and grand-parents has aboriginal \\
& background. \\
& Patients must satisfy the diagnostic criteria of Graves \\
& disease at the time of examination. \\
Exclusion & Patients typical clinical features of hyperthyroidism, diffuse \\
& enlargement of the thyroid gland, increased free thyroxine \\
& or triiodothyronine levels, suppressed thyroid stimulating \\
& hormone levels, positive thyrotrophin-receptor \\
& autoantibodies, and with or without antimicrosomal \\
& or antithyroglobulin antibodies. \\
& Patient is unable to understand or give informed consent. \\
& Patients who had pregnancy or had delivered a \\
baby/babies within one year.
\end{tabular}

To date, several single nucleotide polymorphisms (SNPs) in IL12B have been associated with various immune dysregulations such as systemic lupus erythematosus [22], type 1 diabetes [23], psoriasis and psoriatic arthritis [24], and GD [25]. Although the SNPs and expression of $I L 12 B$ may be associated with autoimmune thyroid diseases, especially GD and GO in Western male populations [26,27], a genetic association between IL12B and GO in oriental populations has not been identified [28]. The aim of this study was to investigate the frequency of $I L 12 B$ variants among GD patients and correlate it with the development of GO in a Taiwan Chinese population.

\section{Methods}

\section{Patients}

A study population of 471 GD patients with or without GO from China Medical University Hospital in Taiwan were enrolled using the inclusion/exclusion criteria summarized in Table 1, which has been published elsewhere $[18,29,30]$. All the methods followed the tenets of the
Declaration of Helsinki. All participants signed the consent form approved by the Institutional Review Board of the China Medical University Hospital. GO was measured by the Hertel exophthalmometer. Patients who satisfied the NOSPECS system recommended by the American Thyroid Association [31] were classified as the GO group: (1) normal upper eyelid position $1.5 \mathrm{~mm}$ below the superior limbus and normal lower eyelid position at the level of the inferior limbus in primary gaze and (2) proptosis defined as the anteroposterior protrusion of the globe $>19 \mathrm{~mm}$ from the lateral orbital rim in either eye or any discrepancy in the degree of protrusion of both eyes by $>1 \mathrm{~mm}$ [32]. Those who did not satisfy both criteria were classified as the non-GO group. All individuals classified as affected were interviewed and examined by experienced clinicians.

\section{SNP selection}

IL12B SNP genotype information from the HapMap $\mathrm{CHB}+$ JPT population was downloaded in December 2008. HapMap genotypes were analyzed within Haploview, and tag SNPs were selected using the Tagger function by applying (i) 0.1 as a threshold minor allele frequency (MAF) for "tag SNPs" in the HapMap CHB + JPT population and (ii) $\geq 0.6$ as the Illumina score as recommended by the manufacturer. Eight polymorphisms within the $I L 12 B$ gene were selected accordingly, including SNPs rs2195940 ( $C / T$ at intron 5$), \mathrm{rs} 2853696(A / G$ at intron 5), rs2421047 ( $A / G$ at intron 4$), \mathrm{rs} 2853694(A / C$ at intron 3), rs2569254 ( $C / T$ at intron 1$), r s 1003199(C / T$ at intron 1), rs7709212 ( $C / T$ at promoter), and rs6868898 ( $C / T$ at promoter).

\section{Genomic DNA extraction and genotyping}

Blood samples were collected by venipuncture and were subsequently subjected to genomic DNA isolation. A genomic DNA kit (Qiagen) was used for genomic DNA extraction. The DNA concentration of each sample was determined before genotyping. All 8 SNPs in the IL12B

Table 2 Eight single nucleotide polymorphisms in the IL12B gene identified from 471 Graves disease patients with or without Graves ophthalmopathy

\begin{tabular}{llllll}
\hline SNPs & Position in IL12B & Chromosome position & Alleles & HWpval & MAF \\
\hline rs2195940 & Intron 5 & 158744352 & C:T & 0.88 & 0.04 \\
\hline rs2853696 & Intron 5 & 158744660 & G:G & 1.00 & 0.53 \\
\hline rs2421047 & Intron 4 & 158746307 & A:G & 0.53 \\
\hline rs2853694 & Intron 3 & 158749088 & A:C & 0.44 & 0.48 \\
\hline rs2569254 & Intron 1 & 158751249 & C:T & 1.00 \\
\hline rs1003199 & Intron 1 & 158755566 & C:T & 0.56 & 0.31 \\
\hline rs7709212 & Promoter & 158764177 & C:T & 0.22 & 0.37 \\
\hline rs6868898 & Promoter & 158764420 & C:T & 0.54 & 0.49 \\
\hline
\end{tabular}

SNP positions in the IL12B gene were numbered upstream (+) or downstream (-) from the IL12B transcription initiation site. Chromosome positions were referred to the sequence of NCBI database (built 37.1). SNP, single nucleotide polymorphism; Hwpval, Hardy-Weinberg equilibrium $P$ value; MAF, minor allele frequency. 
Table 3 Frequencies of genotypes and alleles of single nucleotide polymorphisms in the IL-12B gene in Graves disease patients with or without Graves ophthalmopathy

\begin{tabular}{llll}
\hline SNPs & GD/non-GO & GD/GO & $P$ value ${ }^{a}$ \\
\cline { 2 - 3 } & Number (\%) & Number (\%) & \\
\hline
\end{tabular}

\begin{tabular}{cccc}
\hline $\mathrm{rs} 2195940$ & & & \\
\hline$C / C$ & $247(91.14)$ & $185(92.50)$ & 0.60 \\
\hline$C / T$ & $24(8.86)$ & $15(7.50)$ & \\
\hline$T / T$ & $0(0.00)$ & $0(0.00)$ & \\
\hline$C$ & $518(95.57)$ & $385(96.25)$ & 0.61 \\
\hline$T$ & $24(4.43)$ & $15(3.75)$ &
\end{tabular}

\begin{tabular}{cccc}
\hline$r s 2853696$ & & & - \\
\hline$A / A$ & $0(0.00)$ & $0(0.00)$ & \\
\hline$A / G$ & $0(0.00)$ & $0(0.00)$ & - \\
\hline$G / G$ & $271(100.00)$ & $200(100.00)$ & \\
\hline$A$ & $0(0.00)$ & $0(0.00)$ & \\
\hline$G$ & $542(100.00)$ & $400(100.00)$ & \\
\hline$r s 2421047$ & & & \\
\hline$A / A$ & $56(20.66)$ & $46(23.00)$ & 0.62 \\
\hline$A / G$ & $145(53.51)$ & $98(49.00)$ & \\
\hline$G / G$ & $70(25.83)$ & $56(28.00)$ & \\
\hline$A$ & $257(47.42)$ & $190(47.50)$ & \\
\hline$G$ & $285(52.58)$ & $210(52.50)$ &
\end{tabular}

\begin{tabular}{|c|c|c|c|}
\hline \multicolumn{4}{|c|}{ rs2853694 } \\
\hline A/A & $126(46.49)$ & $92(46.00)$ & 0.99 \\
\hline$A / C$ & $121(44.65)$ & $90(45.00)$ & \\
\hline$C / C$ & $24(8.86)$ & $18(9.00)$ & \\
\hline$A$ & 373 (68.82) & $274(68.50)$ & 0.92 \\
\hline$C$ & $169(31.18)$ & $126(31.50)$ & \\
\hline \multicolumn{4}{|c|}{ rs2569254 } \\
\hline$C / C$ & 189 (69.74) & $140(70.00)$ & 0.85 \\
\hline $\mathrm{C} / \mathrm{T}$ & $76(28.04)$ & $54(27.00)$ & \\
\hline$T / T$ & $6(2.21)$ & $6(3.00)$ & \\
\hline$C$ & 454 (83.76) & $334(83.50)$ & 0.91 \\
\hline$T$ & 88 (16.24) & $66(16.50)$ & \\
\hline \multicolumn{4}{|c|}{ rs1003199 } \\
\hline$C / C$ & $114(42.07)$ & $76(38.00)$ & 0.58 \\
\hline$C / T$ & $121(44.65)$ & $92(46.00)$ & \\
\hline$T / T$ & $36(13.28)$ & $32(16.00)$ & \\
\hline$C$ & 349 (64.39) & $244(61.00)$ & 0.29 \\
\hline$T$ & $193(35.61)$ & $156(39.00)$ & \\
\hline \multicolumn{4}{|c|}{ rs7709212 } \\
\hline$C / C$ & $61(22.51)$ & $56(28.00)$ & 0.16 \\
\hline$C / T$ & $154(56.83)$ & $96(48.00)$ & \\
\hline$T / T$ & $56(20.66)$ & $48(24.00)$ & \\
\hline$C$ & 276 (50.92) & $208(52.00)$ & 0.74 \\
\hline$T$ & $266(49.08)$ & $192(48.00)$ & \\
\hline
\end{tabular}

Table 3 Frequencies of genotypes and alleles of single nucleotide polymorphisms in the IL-12B gene in Graves disease patients with or without Graves ophthalmopathy (Continued)

rs6868898

\begin{tabular}{cccc}
\hline$C / C$ & $42(15.50)$ & $25(12.50)$ & 0.56 \\
\hline$C / T$ & $123(45.39)$ & $89(44.50)$ & \\
\hline$T / T$ & $106(39.11)$ & $86(43.00)$ & \\
\hline$C$ & $276(50.92)$ & $208(52.00)$ & 0.74 \\
\hline$T$ & $266(49.18)$ & $192(48.00)$ & \\
\hline
\end{tabular}

Abbreviations: GD, Graves disease; GO, Graves ophthalmopathy; $\mathrm{Cl}$, confidence interval.

${ }^{\mathrm{a}} P$ values (two-tailed) were calculated using chi-square tests with $3 \times 2$

contingency tables (genotypes; 2 d.f.) or $2 \times 2$ contingency tables (alleles; 1 d.f.).

gene were analyzed using an allele-specific extension and ligation assay (Illumina) following the manufacturer's instructions.

\section{Statistical analysis}

Sample size was determined according to the previous report [33]. We set alpha as 0.05 , where 0 and 1 represent $C$ and $T$ respectively for alleles at rs 1003199 , therefore the mean of all 198 male patients was 0.28 and the SD was 0.49). Associations between each SNP and GO were assessed using the chi-square test. An exact $P$ value (two-tailed) $<0.05$ with Bonferroni adjustment (threshold $P$ value is $0.05 / \mathrm{n}$, where $\mathrm{n}$ is number of all independent tests at the same time) [34] was considered statistically significant. The allelic and genotypic frequencies were compared in GD patients with and without $\mathrm{GO}$, and the odds ratios (ORs) per allele/genotype were estimated by applying unconditional logistic regression with a 95\% confidence interval (CI). All of the above statistical analyses were performed using PASW Statistics 18.0 software. ORs per haplotype were calculated using Haldane's modification of Woolf's equation: $\mathrm{OR}=[(\mathrm{a}+1 / 2) \times(\mathrm{d}+1 / 2)] /[(\mathrm{b}+1 / 2) \times(c+1 / 2)]$, where $\mathrm{a}, \mathrm{b}, \mathrm{c}$, and $\mathrm{d}$ represent the affected number in the $\mathrm{GO}$ group, the affected number in the non-GO group, the non-affected number in the GO group, and the nonaffected number in the non-GO group, respectively, to avoid problems when critical entries are zero [35]. Screening for linkage disequilibrium was performed using Haploview ver. 4.1 [36]. The best locus-locus interaction models were detected with an estimate testing accuracy of $>50 \%$ consistency using the multifactor dimensionality reduction (MDR) 1.1.0 of the opensource MDR software package (Dartmouth Medical School, Hanover, NH). The interaction dendrogram was established according to a hierarchical clustering algorithm [37-40]. 
Table 4 Allele frequencies of single nucleotide polymorphism in IL-12B among male Graves disease patients with or without Graves ophthalmopathy

\begin{tabular}{|c|c|c|c|c|}
\hline \multirow[t]{2}{*}{ SNPs } & GD/nonGO & GD/GO & \multirow[t]{2}{*}{$P$ Value ${ }^{a}$} & \multirow{2}{*}{$\begin{array}{l}\text { Odds ratio } \\
(95 \% \mathrm{Cl}){ }^{b}\end{array}$} \\
\hline & $\overline{\text { Number (\%) }}$ & $\overline{\text { Number (\%) }}$ & & \\
\hline
\end{tabular}

\begin{tabular}{ccc}
\hline rs2195940 & & \\
$C / C$ & $43(89.58)$ & $49(96.08)$ \\
$C / T$ & $5(10.42)$ & $2(3.92)$ \\
$T / T$ & $0(0.00)$ & $0(0.00)$ \\
$C$ & $91(94.79)$ & $100(98.00)$ \\
$T$ & $5(5.21)$ & $2(2.00)$ \\
rs2853696 & & \\
A/A & $0(0.00)$ & $0(0.00)$ \\
$A / G$ & $0(0.00)$ & $0(0.00)$ \\
$G / G$ & $48(100.00)$ & $51(100.00)$ \\
$A$ & $0(0.00)$ & $0(0.00)$ \\
$G$ & $96(100.00)$ & $102(100.00)$
\end{tabular}

rs2421047

\begin{tabular}{|c|c|c|c|c|}
\hline$A / A$ & $9(18.75)$ & $6(11.76)$ & 0.18 & \\
\hline$A / G$ & 32 (66.67) & $30(58.82)$ & & \\
\hline$G / G$ & $7(14.58)$ & $15(29.41)$ & & \\
\hline$A$ & $50(52.08)$ & $42(41.18)$ & 0.12 & \\
\hline$G$ & 46 (47.92) & 60 (58.82) & & \\
\hline \multicolumn{5}{|c|}{ s2853694 } \\
\hline$A / A$ & $26(54.17)$ & $21(41.18)$ & 0.25 & \\
\hline$A / C$ & $20(41.67)$ & $24(47.06)$ & & \\
\hline$C / C$ & $2(4.16)$ & $6(11.76)$ & & \\
\hline$A$ & $72(75.00)$ & $66(64.71)$ & 0.11 & \\
\hline$C$ & $24(25.00)$ & 36 (35.39) & & \\
\hline \multicolumn{5}{|c|}{$s 2569254$} \\
\hline$C / C$ & $32(66.67)$ & $33(64.71)$ & 0.38 & \\
\hline$C / T$ & 16 (33.33) & $16(31.37)$ & & \\
\hline$T / T$ & $0(0.0)$ & $2(3.92)$ & & \\
\hline C & 80 (83.33) & 82 (80.39) & 0.59 & \\
\hline$T$ & $16(16.67)$ & $20(19.61)$ & & \\
\hline \multicolumn{5}{|c|}{ s1003199 } \\
\hline$C / C$ & $23(47.92)$ & $13(25.49)$ & 0.01 & 1 \\
\hline$C / T$ & $23(47.92)$ & $28(54.90)$ & & $4.11(0.82-20.66)$ \\
\hline$T / T$ & $2(4.16)$ & $10(19.61)$ & & 8.85 (1.68-46.69) \\
\hline C & $69(71.88)$ & $54(52.94)$ & $6.00 \times 10^{-3}$ & 1 \\
\hline$T$ & $27(28.12)$ & $48(47.06)$ & & $2.27(1.26-4.10)$ \\
\hline
\end{tabular}

rs7709212

$\begin{array}{cccc}C / C & 14(29.17) & 12(23.53) & 0.82 \\ C / T & 27(56.25) & 31(60.78) & \\ T / T & 7(14.58) & 8(15.69) & \\ C & 55(57.29) & 55(53.92) & 0.63 \\ T & 41(42.71) & 47(46.08) & \end{array}$

Table 4 Allele frequencies of single nucleotide polymorphism in IL-12B among male Graves disease patients with or without Graves ophthalmopathy (Continued)

\begin{tabular}{cccc}
\hline$r s 6868898$ & & & \\
$C / C$ & $5(10.42)$ & $10(19.61)$ & 0.19 \\
$C / T$ & $18(37.50)$ & $23(45.10)$ & \\
$T / T$ & $25(52.08)$ & $18(35.29)$ & \\
$C$ & $28(29.17)$ & $43(42.16)$ & 0.06 \\
$T$ & $68(70.83)$ & $59(57.84)$ &
\end{tabular}

Abbreviations: SNP, single nucleotide polymorphism; GD, Graves disease; GO, Graves ophthalmopathy; $\mathrm{Cl}$, confidence interval.

${ }^{\mathrm{a}} P$ values (two-tailed) were calculated using chi-square tests with $3 \times 2$ contingency tables (genotypes; 2 d.f.) or $2 \times 2$ contingency tables (alleles; 1 d.f.). bodds ratios and $95 \% \mathrm{Cl}$ per genotype and allele were estimated by applying unconditional logistic regression. $P$ values less than 0.05 were considered significant.

\section{Results}

Genotypic frequencies of the IL12B polymorphisms in GD patients

All the samples from 471 GD patients were genotyped for the 8 SNPs in the IL12B gene. All of the tested SNPs in this study were found to be in Hardy-Weinberg equilibrium $(P>0.05$, Table 2$)$. To identify the SNPs associated with clinical features of GD, including GO, goiter, nodular hyperplasia, pretibial myxedema, and vitiligo, the 8 SNPs within the $I L 12 B$ gene were investigated. None of these clinical features were associated with any of the tested $I L 12 B$ polymorphisms (Table 3 and data not shown).

The IL12B polymorphism rs1003199 is significantly associated with the development of GO in male GD patients

In our study, there were many more female patients than male patients (female:male, 3.8:1). Because sex ratio is one variable that can affect the results of case-control association studies, a sex-stratification analysis was performed. Results showed that although no significant difference between $I L 12 B$ SNPs and GO in the female patients was observed, SNP rs1003199 was significantly associated with the development of $\mathrm{GO}$ in the male GD patients: GD patients with the $T$ allele at rs1003199 showed a 1.27 -fold increase in the risk of developing GO compared with GD patients carrying the $C$ allele $\left(P=6.00 \times 10^{-3}\right.$; OR $=2.27,95 \% \mathrm{CI}=$ 1.26-4.10; Table 4). The sample size was large enough (198 individuals) to detect the polymorphism $(\alpha=$ 0.05 , power $=0.88)$. In addition, GD patients with a $T / T$ genotype at rs1003199 showed a 7.85-fold increase in the risk of developing GO compared with GD patients carrying the $C / C$ genotype $(P=0.01$; OR $=$ 8.85, 95\% CI $=1.68-46.69$; Table 4). However, only the significance of the allele distribution at rs1003199 
Table 5 Summary of multifactor dimensionality reduction (MDR) models for gene-gene interaction in male Graves disease patients with Graves ophthalmopathy

\begin{tabular}{lllllll}
\hline Number of factors & Best candidate model & Balance accuracy & CV consistency & $\boldsymbol{X}^{\mathbf{2}}$ & $\boldsymbol{P}$ value & Odds ratio (95\%Cl) \\
\hline 1 & rs1003199 & $59.47 \%$ & $100 / 100$ & 7.53 & $6.00 \times 10^{-3}$ & $2.27(1.26-4.10)$ \\
2 & rs2195940 rs1003199 & $59.50 \%$ & $76 / 100$ & 7.67 & $6.00 \times 10^{-3}$ & $2.30(1.27-4.17)$ \\
3 & rs1003199 rs7709212 rs6868898 & $61.40 \%$ & $100 / 100$ & 10.52 & $1.20 \times 10^{-3}$ & $2.59(1.45-4.62)$ \\
4 & rs2853694 rs1003199 rs7709212 rs6868898 & $53.28 \%$ & $100 / 100$ & 12.47 & $4.00 \times 10^{-4}$ & $2.82(1.58-5.06)$ \\
\hline
\end{tabular}

remained after applying the Bonferroni correction. These results indicate that male GD patients carrying the $T$ allele might be at a higher risk for developing GO than patients carrying other alleles, suggesting the possible role of $I L 12 B$ in the development of $\mathrm{GO}$ in the male GD patients.

\section{Frequencies of the IL12B haplotypes and their associations with GD and GO}

Because our MDR analysis indicated that the best interaction model for the prediction of GO development in male GD patients is the 3-locus model (balance accuracy, 61.40\%; cross-validation consistency $=100 / 100, P=$ $1.20 \times 10^{-3}$; Table 5), we further estimated the association between the haplotype comprising the 3 SNPs rs1003199, rs7709212, and rs6868898 and GO. These results are listed in Table 6 . In the male GD patients, the frequencies of $I L 12 B$ haplotypes were significantly different $\left(P=1.70 \times 10^{-2}\right)$. Although haplotype-specific analysis showed that haplotypes HA5-TCC and HA7-TTC are associated with a higher risk of GO $(P=0.03$; OR: 4.13 and $P=0.02$; OR: 10.89 ; respectively), and haplotype HA2-CCT is associated with a lower risk of developing GO ( $P=0.03$; OR: 0.51$)$, we could not prove the statistical significance of the analysis after applying the Bonferroni correction.

\section{Discussion}

Several reports have documented that genetic factors may play a role in the development of GO [12,13,41,42]: the susceptibility genes for GO may include those encoding the major histocompatibility complex (HLA) class $I$ and class II molecules [12], cytotoxic T-lymphocyteassociated protein 4 (CTLA4) [12], cell surface molecules intercellular adhesion molecule 1 (ICAM1) [43], and integrin alpha E (ITGAE) [29], as well as a variety of immunomodulatory genes, including those encoding the cytokines interferon gamma (IFNG) [26,44], tumor necrosis factor (TNF) [26,45], and interleukin 1 beta (IL1B) [18-20]. IL12B has been identified to possibly influence the development of autoimmune thyroid diseases and the related ophthalmopathy in male patients in the Western world [26,27], but it has not yet been deeply examined in Oriental patients [28]. In this study, we investigated whether IL12B SNPs contributed to the development of GO in a Taiwan Chinese GD population. The results show that none of the tested $I L 12 B$ SNPs were associated with any manifestations of GD. However, the $T$ allele at SNP rs1003199 was significantly associated with the occurrence of GO in male patients. Our results, in part, support the hypothesis that SNPs of pro-inflammatory cytokines may be related to GO development.

Table 6 Estimated frequencies of the haplotypes inferred from rs1003199, rs7709212 and rs6868898 among male Graves disease patients with or without Graves ophthalmopathy

\begin{tabular}{|c|c|c|c|c|c|c|c|c|}
\hline \multirow[t]{2}{*}{ Haplotype } & \multicolumn{3}{|c|}{ SNP } & \multirow{2}{*}{$\frac{\text { GD/nonGO }}{\text { Number (\%) }}$} & \multirow{2}{*}{$\frac{\text { GD/GO }}{\text { Number (\%) }}$} & \multirow[t]{2}{*}{$P$ Value $^{a}$} & \multirow[t]{2}{*}{$P$ Value $^{b}$} & \multirow[t]{2}{*}{ Odds ratio $^{c}$} \\
\hline & rs1003199 & rs7709212 & rs6868898 & & & & & \\
\hline HA1 & $C$ & $C$ & $C$ & $17(17.71)$ & $22(21.57)$ & $1.70 \times 10^{-2}$ & 0.50 & 1.27 \\
\hline $\mathrm{HA} 2$ & C & C & $T$ & $34(35.42)$ & $22(21.57)$ & & 0.03 & 0.51 \\
\hline $\mathrm{HA3}$ & C & $T$ & C & $8(8.33)$ & $4(3.92)$ & & 0.19 & 0.48 \\
\hline $\mathrm{HA} 4$ & $C$ & $T$ & $T$ & $10(10.42)$ & $6(5.88)$ & & 0.24 & 0.55 \\
\hline $\mathrm{HA} 5$ & $T$ & C & C & $0(0.00)$ & $5(4.90)$ & & 0.03 & 10.89 \\
\hline HA6 & $T$ & C & $T$ & $4(4.17)$ & $6(5.88)$ & & 0.58 & 1.38 \\
\hline HA7 & $T$ & $T$ & C & $3(3.13)$ & $12(11.76)$ & & 0.02 & 3.69 \\
\hline HA8 & $T$ & $T$ & $T$ & $20(20.83)$ & $25(24.51)$ & & 0.54 & 1.23 \\
\hline
\end{tabular}

Abbreviations: GD, Graves disease; GO, Graves ophthalmopathy; $\mathrm{Cl}$, confidence interval.

${ }^{a} P$ values (two-tailed) were calculated using chi-square tests with $8 \times 2$ contingency tables (haplotypes; 7 d.f.).

${ }^{\mathrm{b}} P$ values (two-tailed) were calculated using chi-square tests with $2 \times 2$ contingency tables (haplotypes; 1 d.f.)

'Odds ratio was calculated using Haldane's modification of Woolf' equation. 
Theoretical and practical studies suggested that MDR has reasonable power for detecting interactions. Compared to the conventional statistical approaches, MDR was a novel, nonparametric, and genetic model-free approach that was developed specifically to detect not only interactions within or among genes but also interactions between genes and the environment. The MDR method has been used in several diseases such as cancers and inherited diseases [46,47]. However, a disadvantage of this method is that it overemphasizes the large dissimilarities and does not appropriately represent the small dissimilarities. Here, we used the MDR method to identify the interaction between 3 SNPs, including rs1003199 in intron 1 and rs7709212 and rs6868898 in the promoter, and GO. In addition, our preliminary results from a database search (MiRbase, http://www.mirbase.org/ search.shtml) suggest that these SNPs may be miRNA targets. The $C$ allele at rs6868898 showed higher similarity with miRNA sequences than the $T$ allele at rs6868898. Moreover, only the $T$ allele at rs1003199 and the $T$ allele at rs7709212, but not the $C$ allele at rs1003199 and the $C$ allele at rs7709212, showed a similarity with miRNA sequences (Additional file 1). Whether these SNPs, as well as haplotypes, play a role in the development of $\mathrm{GO}$ by regulating the expression of the $I L 12 B$ gene or the stability of the mRNA by miRNA needs further investigation.

The SNP rs6887695, which is located in the promoter region of the $I L 12 B$ gene, may be associated with GO [26,27]. Although it was not selected under our SNP criteria, we also tried to analyze its genotype distribution in our patients, but we failed to find a statistically significant association between SNP rs6887695 and GO. Ethnic differences may be a reason for this discrepancy. Although the results presented here provide new information that may facilitate the understanding of the pathogenesis of GO, additional studies are necessary to confirm this finding in a larger sample and ideally, in a second group of affected and unaffected individuals.

The results of this study also provide novel information for identifying the mechanisms underlying the pathogenesis of GO. It has long been established that GO is a complex disease with a variety of weak-effect genes that are influenced by a wide range of environmental factors such as sex, iodine status, smoking, infectious agents, and stress. However, the reasons for the significant female preponderance of GD and GO are not well understood, but they may include skewed X chromosome inactivation [48], fetal microchimerism [49], or sex hormone effects [50]. In view of the significant sex-specific variation in $\mathrm{GO}$, genetic factors may influence the establishment of differential risk between affected women and men. This study demonstrated that the polymorphisms of the $I L 12 B$ gene may influence the development of GO. However, because of the lack of a larger sample size and published functional studies on these polymorphisms, the mechanisms of the associated polymorphisms need to be fully examined for their capacity to alter the GO phenotype. In addition, to confirm the disease-associated SNPs, further investigations on the role of the $I L 12 B$ gene in GO development at the molecular level are warranted.

\section{Conclusion}

In summary, this study showed that the $I L 12 B$ polymorphisms may be associated with GO in Taiwan Chinese GD patients in a sex-specific manner. Whether these results can provide valuable insights requires further genetic and biological studies of the specific SNPs and haplotypes.

\section{Additional file}

Additional file 1: Table S1. Prediction of polymorphisms of biological

relevance in miRNA target sites.

\section{Abbreviations}

GD: Graves disease; GO: Graves ophthalmopathy; SNP: Single nucleotide polymorphisms; IL12B: Interleukin 12B; MAF: Minor allele frequency; OR: Odds ratio; Cl: Confidence interval; MDR: Multifactor dimensionality reduction; HLA: Major histocompatibility complex; CTLA4: Cytotoxic T-lymphocyteassociated protein 4; ICAM1: Cell surface molecules intracellular adhesion molecule 1; ITGAE: Integrin alpha E; IFNG: Interferon gamma; TNF: Tumor necrosis factor; IL1B: Interleukin 1 beta.

\section{Competing interests}

The authors declare that they have no competing interests.

\section{Authors' contributions}

YHL: conception, design, analysis, statistical and logistical support, interpretation, literature search and article writing of the study; CCC: provision of patients, data collection and critical review of the study; LLL: statistical and logistical support of the study; LW: technique support of the study; CHT: obtaining funding of the study; FJT: obtaining funding of the study and final approval of the article. All authors read and approved the final manuscript.

\section{Acknowledgements}

We thank all donors enrolled in the present study. This study was supported by grants from China Medical University (CMU-100-N1-03-1) and China Medical University Hospital (DMR-100-162), Taichung, Taiwan.

\section{Author details}

'Department of Medical Genetics and Medical Research, China Medical University Hospital, Taichung, Taiwan. ${ }^{2}$ Graduate Institute of Integrated Medicine, China Medical University, Taichung, Taiwan. ${ }^{3}$ Division of Endocrinology and Metabolism, Department of Medicine, China Medical University Hospital, Taichung, Taiwan. ${ }^{4}$ Department of Endocrinology and Metabolism, College of Chinese Medicine, China Medical University, Taichung, Taiwan. ${ }^{5}$ Department of Health Management, I Shou University, Kaohsiung, Taiwan. ${ }^{6}$ School of Chinese Medicine, China Medical University, Taichung, Taiwan. ${ }^{7}$ Department of Pediatrics, China Medical University Hospital, Taichung, Taiwan. ${ }^{8}$ Asia University, Taichung, Taiwan. ${ }^{9}$ School of Post-Baccalaureate Chinese Medicine, China Medical University, Taichung Taiwan. ${ }^{10}$ Department of Biotechnology, Asia University, Taichung, Taiwan. ${ }^{11}$ Department of Biotechnology and Bioinformatics, Asia University, Taichung, Taiwan. 
Received: 27 March 2012 Accepted: 2 November 2012

Published: 19 November 2012

\section{References}

1. Kuriyan AE, Phipps RP, Feldon SE: The eye and thyroid disease. Curr Opin Ophthalmol 2008, 19:499.

2. Meyer Zu Horste M, Stroher E, Berchner-Pfannschmidt U, Schmitz-Spanke S, Pink M, Gothert JR, Fischer JW, Gulbins E, Eckstein AK: A novel mechanism involved in the pathogenesis of Graves ophthalmopathy (GO): clathrin is a possible targeting molecule for inhibiting local immune response in the orbit. J Clin Endocrinol Metab 2011, 96:E1727.

3. van Steensel L, Dik WA: The orbital fibroblast: a key player and target for therapy in graves' ophthalmopathy. Orbit 2010, 29:202.

4. Smith TJ: Insights into the role of fibroblasts in human autoimmune diseases. Clin Exp Immunol 2005, 141:388.

5. Smith TJ: Pathogenesis of Graves' orbitopathy: a 2010 update. J Endocrinol Invest 2010, 33:414.

6. Bahn RS: TSH receptor expression in orbital tissue and its role in the pathogenesis of Graves' ophthalmopathy. J Endocrinol Invest 2004, 27:216.

7. Kumar S, Nadeem S, Stan MN, Coenen M, Bahn RS: A stimulatory TSH receptor antibody enhances adipogenesis via phosphoinositide 3-kinase activation in orbital preadipocytes from patients with Graves' ophthalmopathy. J Mol Endocrinol 2011, 46:155

8. Massart C, Sapin R, Gibassier J, Agin A, d'Herbomez M: Intermethod variability in TSH-receptor antibody measurement: implication for the diagnosis of Graves disease and for the follow-up of Graves ophthalmopathy. Clin Chem 2009, 55:183.

9. Yin $X$, Latif $R$, Bahn $R$, Tomer $Y$, Davies TF: Influence of the TSH receptor gene on susceptibility to Graves' disease and Graves' ophthalmopathy. Thyroid 2008, 18:1201.

10. Smith TJ: The putative role of fibroblasts in the pathogenesis of Graves' disease: evidence for the involvement of the insulin-like growth factor-1 receptor in fibroblast activation. Autoimmunity 2003, 36:409.

11. Khoo TK, Bahn RS: Pathogenesis of Graves' ophthalmopathy: the role of autoantibodies. Thyroid 2007, 17:1013.

12. Bednarczuk T, Gopinath B, Ploski R, Wall JR: Susceptibility genes in Graves' ophthalmopathy: searching for a needle in a haystack? Clin Endocrinol (Oxf) 2007, 67:3

13. Ajjan RA, Weetman AP: New understanding of the role of cytokines in the pathogenesis of Graves' ophthalmopathy. J Endocrinol Invest 2004, 27:237.

14. Luther SA, Cyster JG: Chemokines as regulators of T cell differentiation. Nat Immunol 2001, 2:102

15. Mascanfroni I, Montesinos Mdel M, Susperreguy S, Cervi L, llarregui JM, Ramseyer VD, Masini-Repiso AM, Targovnik HM, Rabinovich GA, Pellizas CG: Control of dendritic cell maturation and function by triiodothyronine. FASEB J 2008, 22:1032.

16. Ajjan RA, Watson PF, Weetman AP: Detection of IL-12, IL-13, and IL-15 messenger ribonucleic acid in the thyroid of patients with autoimmune thyroid disease. J Clin Endocrinol Metab 1997, 82:666

17. Wakelkamp IM, Bakker O, Baldeschi L, Wiersinga WM, Prummel MF: TSH-R expression and cytokine profile in orbital tissue of active vs. inactive Graves' ophthalmopathy patients. Clin Endocrinol (Oxf) 2003, 58:280.

18. Liu YH, Chen RH, Wu HH, Liao WL, Chen WC, Tsai Y, Tsai CH, Wan L, Tsai FJ: Association of interleukin-1beta (IL1B) polymorphisms with Graves' ophthalmopathy in Taiwan Chinese patients. Invest Ophthalmol Vis Sci 2010, 51:6238

19. Khalilzadeh $\mathrm{O}$, Anvari M, Esteghamati A, Mahmoudi M, Tahvildari M, Rashidi A, Khosravi F, Amirzargar A: Graves' ophthalmopathy and gene polymorphisms in interleukin-1alpha, interleukin-1beta, interleukin-1 receptor and interleukin-1 receptor antagonist. Clin Experiment Ophthalmol 2009, 37:614

20. Liu N, Li X, Liu C, Zhao Y, Cui B, Ning G: The association of interleukin-1alpha and interleukin-1beta polymorphisms with the risk of Graves' disease in a case-control study and meta-analysis. Hum Immunol 2010, 71:397.

21. Liu FL, Chen $\mathrm{CH}$, Chu SJ, Chen JH, Lai JH, Sytwu HK, Chang DM: Interleukin (IL)-23 p19 expression induced by IL-1beta in human fibroblast-like synoviocytes with rheumatoid arthritis via active nuclear factor-kappaB and AP-1 dependent pathway. Rheumatology (Oxford) 2007, 46:1266.

22. Miteva LD, Manolova IM, Ivanova MG, Rashkov RK, Stoilov RM, Gulubova MV Stanilova SA: Functional genetic polymorphisms in interleukin-12B gene in association with systemic lupus erythematosus. Rheumatol Int 2012, 32:53.

23. Yang JM, Nagasaka S, Yatagai T, Nakamura T, Kusaka I, Ishikawa SE, Saito T, Ishibashi S: Interleukin-12p40 gene (IL-12B) polymorphism and Type 1 diabetes mellitus in Japanese: possible role in subjects without having high-risk HLA haplotypes. Diabetes Res Clin Pract 2006, 71:164.

24. Liu Y, Helms C, Liao W, Zaba LC, Duan S, Gardner J, Wise C, Miner A, Malloy MJ, Pullinger CR, Kane JP, Saccone S, Worthington J, Bruce I, Kwok PY, Menter A, Krueger J, Barton A, Saccone NL, Bowcock AM: A genome-wide association study of psoriasis and psoriatic arthritis identifies new disease loci. PLoS Genet 2008, 4:e1000041.

25. Anvari M, Khalilzadeh O, Esteghamati A, Momen-Heravi F, Mahmoudi M, Esfahani SA, Rashidi A, Amirzargar A: Graves' disease and gene polymorphism of TNF-alpha, IL-2, IL-6, IL-12, and IFN-gamma. Endocrine 2010, 37:344.

26. Anvari M, Khalilzadeh O, Esteghamati A, Esfahani SA, Rashidi A, Etemadi A, Mahmoudi M, Amirzargar AA: Genetic susceptibility to Graves' ophthalmopathy: the role of polymorphisms in proinflammatory cytokine genes. Eye (Lond) 2010, 24:1058.

27. Walsh JP, Berry J, Liu S, Panicker V, Dayan CM, Brix TH, Hegedus L, Hou P, Shi B, Morahan G: The clinical presentation of autoimmune thyroid disease in men is associated with IL12B genotype. Clin Endocrinol (Oxf) 2011, 74:508.

28. Hiromatsu Y, Fukutani T, Ichimura M, Mukai T, Kaku H, Miyake I, Yamada K: Interleukin-12B gene polymorphism does not confer susceptibility to Graves' ophthalmopathy in Japanese population. Endocr J 2006, 53:753.

29. Liu YH, Chen RH, Chen WC, Tsai Y, Wan L, Tsai FJ: Disease association of the CD103 polymorphisms in Taiwan Chinese Graves' ophthalmopathy patients. Ophthalmology 2010, 117:1645

30. Liu YH, Wan L, Chang CT, Liao WL, Chen WC, Tsai Y, Tsai CH, Tsai FJ: Association between copy number variation of complement component C4 and Graves' disease. J Biomed Sci 2011, 18:71.

31. Werner SC: Modification of the classification of the eye changes of Graves' disease: recommendations of the Ad Hoc Committee of the American Thyroid Association. J Clin Endocrinol Metab 1977, 44:203.

32. Quant JR, Woo GC: Normal values of eye position and head size in Chinese children from Hong Kong. Optom Vis Sci 1993, 70:668.

33. Cohen J: A power primer. Psychol Bull 1992, 112:155.

34. Bland JM, Altman DG: Multiple significance tests: the Bonferroni method. BMJ 1995, 310:170

35. Svejgaard A, Ryder LP: HLA and disease associations: detecting the strongest association. Tissue Antigens 1994, 43:18.

36. Barrett JC, Fry B, Maller J, Daly MJ: Haploview: analysis and visualization of LD and haplotype maps. Bioinformatics 2005, 21:263.

37. Brassat D, Motsinger AA, Caillier SJ, Erlich HA, Walker K, Steiner LL, Cree BA Barcellos LF, Pericak-Vance MA, Schmidt S, Gregory S, Hauser SL, Haines JL, Oksenberg JR, Ritchie MD: Multifactor dimensionality reduction reveals gene-gene interactions associated with multiple sclerosis susceptibility in African Americans. Genes Immun 2006, 7:310.

38. Hahn LW, Ritchie MD, Moore JH: Multifactor dimensionality reduction software for detecting gene-gene and gene-environment interactions. Bioinformatics 2003, 19:376.

39. Coffey CS, Hebert PR, Ritchie MD, Krumholz HM, Gaziano JM, Ridker PM, Brown NJ, Vaughan DE, Moore JH: An application of conditional logistic regression and multifactor dimensionality reduction for detecting gene-gene interactions on risk of myocardial infarction: the importance of model validation. BMC Bioinformatics 2004, 5:49.

40. Ritchie MD, Hahn LW, Moore JH: Power of multifactor dimensionality reduction for detecting gene-gene interactions in the presence of genotyping error, missing data, phenocopy, and genetic heterogeneity. Genet Epidemiol 2003, 24:150.

41. Dittmar M, Kahaly GJ: Immunoregulatory and susceptibility genes in thyroid and polyglandular autoimmunity. Thyroid 2005, 15:239.

42. Grivell L: Mining the bibliome: searching for a needle in a haystack? New computing tools are needed to effectively scan the growing amount of scientific literature for useful information. EMBO Rep 2002, 3:200.

43. Wang S, Sun H, Chen HY, Zhao ZF, Yang Y, Zhao YJ, Cui B, Ning G: Intercellular adhesion molecule 1 gene polymorphisms do not contribute to Graves' disease in Chinese patients. Endocrine 2007, $31: 114$ 
44. Siegmund $\mathrm{T}$, Usadel $\mathrm{KH}$, Donner $\mathrm{H}$, Braun J, Walfish PG, Badenhoop K: Interferon-gamma gene microsatellite polymorphisms in patients with Graves' disease. Thyroid 1998, 8:1013.

45. Bednarczuk T, Hiromatsu Y, Seki N, Ploski R, Fukutani T, Kurylowicz A Jazdzewski K, Chojnowski K, Itoh K, Nauman J: Association of tumor necrosis factor and human leukocyte antigen DRB1 alleles with Graves' ophthalmopathy. Hum Immunol 2004, 65:632.

46. Motsinger AA, Ritchie MD: Multifactor dimensionality reduction: an analysis strategy for modelling and detecting gene-gene interactions in human genetics and pharmacogenomics studies. Hum Genomics 2006 2:318

47. Ritchie MD: Bioinformatics approaches for detecting gene-gene and gene-environment interactions in studies of human disease. Neurosurg Focus 2005, 19:E2.

48. Brix TH, Knudsen GP, Kristiansen M, Kyvik KO, Orstavik KH, Hegedus L: High frequency of skewed X-chromosome inactivation in females with autoimmune thyroid disease: a possible explanation for the female predisposition to thyroid autoimmunity. J Clin Endocrinol Metab 2005, 90:5949.

49. Ando T, Imaizumi M, Graves PN, Unger P, Davies TF: Intrathyroidal fetal microchimerism in Graves' disease. J Clin Endocrinol Metab 2002, 87:3315.

50. Ansar Ahmed S, Penhale WJ, Talal N: Sex hormones, immune responses, and autoimmune diseases. Mechanisms of sex hormone action. Am J Pathol 1985, 121:531.

doi:10.1186/1423-0127-19-97

Cite this article as: Liu et al:: Association of $I L 12 B$ polymorphisms with susceptibility to Graves ophthalmopathy in a Taiwan Chinese population. Journal of Biomedical Science 2012 19:97.

\section{Submit your next manuscript to BioMed Central and take full advantage of:}

- Convenient online submission

- Thorough peer review

- No space constraints or color figure charges

- Immediate publication on acceptance

- Inclusion in PubMed, CAS, Scopus and Google Scholar

- Research which is freely available for redistribution 